\title{
USO FERTILIZANTE DO SUBPRODUTO DA AGROINDÚSTRIA PROCESSADORA DE GOIABAS I - ATRIBUTOS QUÍMICOS DO SOLO ${ }^{1}$
}

\author{
HENRIQUE ANTUNES DE SOUZA², DANILO EDUARDO ROZANE², \\ DANIEL ANGELUCCI DE AMORIM ${ }^{4}$, VIVIANE CRISTINA MODESTO ${ }^{5}$, \\ WILLIAM NATALE 6
}

RESUMO - A utilização de fontes alternativas de nutrientes, provenientes especialmente de resíduos e subprodutos da agroindústria, pode ser estratégia importante na ciclagem de elementos essenciais, garantindo destino adequado de materiais que seriam descartados. Assim, objetivou-se avaliar a aplicação de doses do subproduto da indústria processadora de goiabas sobre a fertilidade de um Argissolo, sob pomar de goiabeiras. As doses de resíduo foram estabelecidas em função dos teores de $\mathrm{N}$ no material. O delineamento empregado foi o de blocos casualizados, com cinco tratamentos e quatro repetições, sendo as doses do resíduo (moído) iguais a: zero; 9; 18; 27 e $36 \mathrm{t} \mathrm{ha}^{-1}$ (peso do material seco). Foram feitas cinco aplicações do subproduto em: 2006, 2007, 2008, 2009 e 2010. O subproduto da indústria processadora de goiabas promoveu alterações na fertilidade do solo do pomar. Com o aumento das doses, houve incremento das concentrações de fósforo no solo em todas as análises realizadas. As concentrações de manganês aumentaram, e houve redução do valor $\mathrm{pH}$ do solo nos últimos anos de condução do experimento. Observou-se, na camada subsuperfical (0,20-0,40 m), após a aplicação contínua do subproduto, aumento na concentração de fósforo em função das doses do subproduto.

Termos para indexação: Psidium guajava; Adubação; Fertilidade do solo.

\section{AGRONOMIC USE OF BY-PRODUCT OF GUAVA PROCESSING INDUSTRY - I - CHEMICAL SOIL PROPERTIES}

\begin{abstract}
The use of alternative sources of nutrients coming especially from waste and industrial by-products can be an important strategy in nutrient cycling, ensuring proper destination of materials that would otherwise be discarded. The objective was to evaluate the application of doses of by-product of guava processing industry on fertility of an Ultisol in a guava orchard. Doses of waste were established on the basis of $\mathrm{N}$ content in the material. The experimental design was a randomized block design with five treatments and four replications, the doses of the residue equal to zero, 9, 18, 27 and $36 \mathrm{t} \mathrm{ha}^{-1}$ (dry weight of the material). There were five applications residue: in 2006, 2007, 2008, 2009 and 2010. The by-product of the guava processing industry promoted changes in soil fertility in the orchard. With increasing doses increased the concentrations of phosphorus in the soil in all analyzes. The manganese concentrations increased and decreased the soil $\mathrm{pH}$ value in the last years of the experiment. It was observed in the subsuperfical layer $(0.20-0.40 \mathrm{~m})$ after continuous application of by-product an increase in phosphorus concentration as a function of the doses of the by-product.
\end{abstract}

Index terms: Psidium guajava; Fertilization; Fertility of soil.

\footnotetext{
${ }^{1}$ (Trabalho 355-13). Recebido em: 27-09-2013. Aceito para publicação em: 16-04-2014.Suporte financeiro FAPESP e CNPq. ${ }^{2}$ Pesquisador Embrapa/CNPC. Estrada Sobral/Groaíras, km 4, 62.010-970, Sobral-CE. E-mail: henrique.souza@embrapa.br ${ }^{3}$ Professor Unesp-Câmpus de Registro. Av. Nelson Brihi Badur, 430, Vila Tupy, 11.900-000, Registro-SP. E-mail: danilorozane@ registro.unesp.br

${ }^{4}$ Pesquisador Epamig. Rua Afonso Rato, 1301, 38.060-040, Uberaba-MG. E-mail: daniel@epamig.br

${ }^{5}$ Pós-graduanda, Unesp-Câmpus de Jaboticabal. Via de Acesso Prof. Paulo Donato Castellane, s/n, 14.884-900 - Jaboticabal-SP. E-mail: vivianemodesto@hotmail.com

${ }^{6}$ Professor Unesp-Câmpus de Jaboticabal. E-mail: natale@fcav.unesp.br
} 


\section{INTRODUÇÃO}

O Brasil tem área aproximada de 16 mil hectares de goiabeiras plantadas, sendo o maior produtor de goiabas-vermelhas do mundo, gerando anualmente cerca de 340 mil toneladas da fruta, com destaque para o Estado de São Paulo, o maior produtor do País (IBGE, 2012).

$\mathrm{O}$ incremento da atividade agroindustrial no setor frutícola brasileiro tem acarretado, nas últimas décadas, a geração de resíduos ou subprodutos de maneira proporcional. A proibição de utilização de certos resíduos (lodos, de origem animal, etc.), bem como o desconhecimento de seu potencial de uso na agricultura têm conduzido, muitas vezes, ao descarte desses materiais em aterros sanitários, criando, assim, mais um passivo ambiental.

A carência de informações científicas, embasadas em experimentação de campo de longa duração, induz à baixa eficiência de uso dos subprodutos gerados pelas agroindústrias, observando-se que o solo é utilizado mais como meio de descarte desses materiais do que para seu aproveitamento racional (LIMA et al., 2007; CHEPOTE, 2003; MANTOVANI et al., 2005; PRIMO et al., 2010; ARAÚJO et al., 2008; COSTA et al., 2009; GUIMARÃES et al., 2012; GIANELLO et al., 2011).

A atividade agrícola, e em especial a fruticultura, devido à perenidade dos pomares, deve buscar a melhoria da fertilidade do solo, baseado em sistemas de produção duráveis, tanto ambiental, como economicamente sustentáveis.

Nas regiões produtoras de goiaba, cujo objetivo é a transformação industrial (processamento da fruta para confecção de geleias e outros doces), o descarte de resíduos gerados no processo pode causar problemas ambientais. Embora esse subproduto possa ser considerado uma fonte de nutrientes (MANTOVANI et al., 2004; CORREA et al., 2005; SOUZA et al., 2011), sua aplicação nos pomares pode provocar desequilíbrios quantitativos na oferta de elementos às plantas. Pode-se considerar que esse material é um adubo orgânico não balenceado, visto não atender às exigências da planta, necessitando de complementação de outras fontes para garantir nutrição adequada das goiabeiras.

Não foram encontrados na literatura estimativas da quantidade de subproduto da indústria processadora de goiabas gerada no Brasil, mas podem ser feitas algumas considerações, baseadas em dados estatísticos que constam do anuário do IBGE (2012). A produção de goiabas no Brasil é de 342 mil toneladas. Desse total, $36 \%$ são produzidas em São Paulo, ou seja, 125 mil t por ano, sendo aproximadamente $55 \%$ da produção destinada à industrialização. Considerando-se que uma tonelada de goiabas industrializadas gera, em média, $80 \mathrm{~kg}$ de resíduo (8\%), estima-se que a geração do subproduto no Estado seja de 5,5 mil t por ano.

Em vista do volume desse material gerado anualmente, a utilização agrícola do subproduto pode ser uma alternativa viável e racional de reciclagem, diante do razoável teor de nitrogênio (MANTOVANI et al., 2004), além de outros elementos nele contidos.

Considerando-se o potencial agrícola de utilização do subproduto da indústria processadora de goiabas como fornecedor de elementos essenciais, este trabalho foi desenvolvido para avaliar os efeitos da aplicação de diferentes doses desse material sobre os atributos químicos do solo de um pomar comercial de goiabeiras.

\section{MATERIAL E MÉTODOS}

O experimento foi desenvolvido em um pomar comercial de goiabeiras adultas, com oito anos de idade, cultivar Paluma (a mais plantada em todo o Brasil atualmente (NATALE et al., 2009), propagadas vegetativamente. Durante a condução do experimento, o pomar foi irrigado, tendo-se microaspersores tipo bailarina (31 litros por hora), por planta, que era acionado quando a tensiometria na camada de $0-0,20 \mathrm{~m}$ indicava $60 \%$ da capacidade de campo, sendo a água proveniente de poço semiartesiano. O espaçamento das goiabeiras era de $7 \mathrm{~m}$ entre linhas e $5 \mathrm{~m}$ entre árvores, padrão para a cultivar. A área experimental está localizada na maior região produtora de goiabas do Estado de São Paulo, município de Vista Alegre do Alto, com coordenadas geográficas $21^{\circ} 08^{\prime}$ sul, $48^{\circ} 30^{\prime}$ oeste e altitude de $603 \mathrm{~m}$.

Antes da implantação do experimento, coletaram-se na área do pomar 20 subamostras de terra, para compor a amostra composta, tanto na projeção da copa das goiabeiras como na entrelinha da cultura, a fim de avaliar a fertilidade do solo. A terra foi analisada quimicamente (RAIJ et al., 2001), nas camadas de 0-0,20 e 0,20-0,40 m de profundidade. Os resultados das análises químicas, para fins de fertilidade, encontram-se na Tabela 1, e os dados da classificação pedológica, na Tabela 2.

De acordo com as indicações de Natale et al. (1996a), as condições de saturação por bases e fertilidade do solo estavam adequadas para a cultura da goiaba, conforme indica a Tabela 1 , não necessitando de correção da acidez e apresentando concentrações de nutrientes dentro das classes de 
fertilidade do solo indicadas como adequadas para o Estado de São Paulo (RAIJ et al., 1997).

O solo do pomar foi classificado comoArgissolo Vermelho-Amarelo epieutrófico, endodistrófico, textura arenosa/média, correspondendo ao Argissolo Vermelho-Amarelo distrófico, segundo a EMBRAPA (1999).

O subproduto gerado pela indústria processadora de goiabas utilizado no presente estudo é um material constituído basicamente de sementes, junto com alguma fração de epiderme e polpa não separadas no processo físico de despolpamento realizado no processo de transformação industrial que ocorre após a lavagem dos frutos.

O subproduto (pequena fração de polpa e sementes) foi obtido na Indústria de Polpas e Conservas Val Ltda., localizada no município de Vista Alegre do Alto-SP. Realizou-se no material (subproduto - pequena fração de polpa e sementes) a determinação da umidade gravimétrica (secagem a $67 \pm 2{ }^{\circ} \mathrm{C}$ em estufa de circulação forçada de ar). $\mathrm{O}$ material apresentou teor de água de 6,45\% para sementes moídas, que foram submetidas às determinações químicas (Tabela 3), conforme metodologia descrita por Abreu et al. (2006). O $\mathrm{pH}\left(\mathrm{CaCl}_{2}\right)$ do subproduto foi obtido por medida direta na amostra, conforme Abreu et al. (2006) e Raij et al. (2001), cujo valor foi de 4,7. Segundo a legislação vigente (BRASIL, 2009), que regulamenta as especificações de compostos e biofertilizantes, o subproduto atenderia às exigências como matériaprima para classificação como fertilizante orgânico simples, classe "A". A Tabela 3 contém os teores de nutrientes no subproduto.

A primeira aplicação do subproduto no pomar foi realizada em março de 2006 (instalação do experimento); a segunda, terceira, quarta e quinta aplicações foram feitas no início de cada ano, respectivamente, em 2007, 2008, 2009 e 2010.

O delineamento experimental foi em blocos casualizados, com cinco tratamentos e quatro repetições. Empregaram-se cinco doses do subproduto (moído - passado em triturador de forrageira): zero; 9; 18 (dose-padrão); 27 e $36 \mathrm{t} \mathrm{ha}^{-1}$ (peso seco). Essas doses foram estabelecidas em função dos teores de nitrogênio no subproduto, tendo em vista ser o $\mathrm{N}$ o elemento mais caro em termos de custo de produção de fertilizantes, e considerando-se os relativamente altos teores desse macronutriente presentes no material. Além disso, a dose-padrão foi calculada para atender à demanda de $\mathrm{N}$ da cultura da goiaba, de acordo com Natale et al. (1996a). Durante a condução do experimento, não houve qualquer complementação com adubação mineral.
As parcelas experimentais constituíram-se de cinco plantas, correspondendo à área total de 175 $\mathrm{m}^{2}$, e a área útil, de $105 \mathrm{~m}^{2}$, sendo as três goiabeiras centrais consideradas úteis para as avaliações, e as duas árvores das extremidades, bordaduras.

A aplicação do subproduto foi realizada manualmente, sem incorporação ao solo, sendo a dose equivalente de cada tratamento por parcela, dividida em aplicações individuais para cada planta, no espaçamento das mesmas, buscando-se atenuar os eventuais erros de distribuição, dadas as grandes quantidades de material empregadas.

Foram analisadas as características químicas do solo nas profundidades de 0,00-0,20 e 0,20-0,40 $\mathrm{m}$ (na projeção da copa). A amostragem foi realizada com trado tipo holandês, em quatro pontos por planta, sob as três plantas úteis de cada parcela, para formar uma amostra composta. Após coletado, o solo foi seco ao ar e passado em peneira de $2 \mathrm{~mm}$ de abertura de malha, sendo caracterizado quimicamente para fins de fertilidade, segundo Raij et al. (2001). A amostragem de solo foi efetuada anualmente, sempre antecedendo a aplicação do subproduto no ano seguinte, realizada no mês de janeiro do ano subsequente.

Os resultados foram submetidos à análise de variância e, quando significativos, aplicou-se a regressão polinomial, empregando-se o programa estatístico SISVAR (FERREIRA, 2011).

\section{RESULTADOS E DISCUSSÃO}

Na Tabela 4, estão apresentados os resultados da análise de rotina, micronutrientes e enxofre, da camada de 0-0,20 m, referentes às amostragens de solo realizadas em 2006, 2007, 2008, 2009 e 2010.

Verifica-se que, em 2006, não houve efeito significativo das doses do subproduto sobre os atributos do solo, o que pode ser justificado pelo pouco tempo decorrido entre a aplicação do material (março) e a amostragem de solo (dezembro).

Mantovani et al. (2004), trabalhando com este mesmo tipo de subproduto, porém não moído e em condições de casa de vegetação, concluíram que o subproduto do processamento de goiabas é fonte de liberação lenta de nutrientes, mesmo em ambiente controlado. Os dados aqui apresentados, resultantes da aplicação do subproduto há menos de um ano, confirmam que, também em condições de campo, os efeitos benéficos de tal material demandam tempo para se fazerem presentes.

Considerando a análise química do subproduto presente na Tabela 3, na dose-padrão (18 $\left.\mathrm{t} \mathrm{ha}^{-1}\right)$, o aporte de nutrientes seria de aproximadamente 209; 
$38 ; 41 ; 14 ; 16 ; 23\left(\mathrm{~kg} \mathrm{ha}^{-1}\right) ; 180 ; 180 ; 2.700 ; 216 \mathrm{e}$ $504\left(\mathrm{~g} \mathrm{ha}^{-1}\right)$, respectivamente, de N, P, K, Ca, Mg, S, $\mathrm{B}, \mathrm{Cu}, \mathrm{Fe}, \mathrm{Mn}$ e $\mathrm{Zn}$.

Em 2007, houve efeito significativo das doses do subproduto para $\mathrm{P}, \mathrm{Ca}$ e acidez potencial (Tabela 4), cuja análise de regressão para essas variáveis mostrou que o melhor modelo de resposta foi o linear (Tabela 6; Figura 1). Observa-se, na Figura 1, aumento da concentração de $\mathrm{P}$ no solo, em função da elevação das doses do subproduto da indústria de processamento de goiabas. Mantovani et al. (2004) também obtiveram aumentos nas concentrações de $\mathrm{P}$ e K no solo, trabalhando com o mesmo tipo de material, em condições de casa de vegetação. Dentre os vários nutrientes de que as plantas necessitam para o seu desenvolvimento, o fósforo ocupa lugar de destaque, devido à carência na maioria dos solos brasileiros, mesmo que as plantas perenes adultas, incluindo-se as frutíferas, sejam pouco responsivas ao elemento (NATALE et al., 2001). Observa-se, também, diminuição na concentração de $\mathrm{Ca}$ e aumento do $\mathrm{H}+\mathrm{Al}$ com o incremento das doses do subproduto (Tabela 6). Dentre os macronutrientes presentes no subproduto, o Ca é o que apresenta menor teor (Tabela 3), no entanto este nutriente é o terceiro em maior acúmulo em mudas (FRANCO et al., 2007) e apresenta uma exportação média de $6,5 \mathrm{~kg} \mathrm{ha}^{-1}$ em goiabeira Paluma, segundo Natale et al. (1994); assim, as doses aplicadas não foram suficientes para suprir a demanda da planta. Com relação ao potencial hidrogeniônico no solo, ressaltase que o subproduto apresenta valor de 4,7, e ainda a diminuição do $\mathrm{pH}$ pode ser devido à liberação de ácidos orgânicos e nitrificação do amônio, como comentado por Mello e Vitti (2002).

Corrêa et al. (2005), trabalhando com o mesmo tipo de subproduto, porém em condições de laboratório, observaram redução no valor $\mathrm{pH}$ do solo em função do aumento das doses do material empregado. Rozane et al. (2013), estudando a incubação do subproduto da indústria processadora de goiabas em um Argissolo, verificaram incremento nas concentrações de M.O., K, Mg e (H+Al), bem como aumento nos valores de soma de bases e CTC, após 180 dias de incubação.

As concentrações de B e de Mn, no presente estudo, apresentaram resultados significativos na amostragem de 2007, constatando-se aumentos nas concentrações destes micronutrientes à medida que se elevaram as doses de subproduto (Tabelas 4 e 6). O aumento da concentração de Mn disponível no solo, em função do incremento das doses do subproduto, está associado à possível acidificação do solo. Apesar de, na presente análise, não ter sido constatada diminuição do valor $\mathrm{pH}$, houve aumento da acidez potencial. Rozane et al. (2013), trabalhando com o mesmo tipo de subproduto, também constataram incremento nas concentrações de boro no solo com a elevação das doses do subproduto, em avaliação realizada após 180 dias de incubação.

A amostragem de 2008 revelou resultado significativo para o $\mathrm{P}$, em que o melhor modelo de resposta à aplicação do subproduto foi o linear crescente (Figura 1). Houve, ainda, resultados significativos para B, Cu, Fe e Mn (Tabela 6), com incremento linear das concentrações desses micronutrientes no solo em função do aumento das doses.

As doses do subproduto não afetaram os teores de matéria orgânica do solo, porém verificase que o material está mineralizando-se, pois é fonte de vários elementos, sendo que o fósforo e o boro apresentaram incremento linear por dois anos consecutivos.

Houve efeito significativo das doses de subproduto na amostragem realizada em 2009 para as seguintes variáveis: fósforo, acidez potencial e saturação por bases (Tabela 4). Com relação ao fósforo, como já verificado nas duas últimas amostragens de solo, o melhor modelo de resposta foi o linear crescente (Figura 1). Portanto, o subproduto pode ser considerado fonte desse elemento. É notória a carência desse macronutriente em solos tropicais e, em especial, no Brasil (RAIJ, 2011). Desse modo, o subproduto da indústria processadora de goiabas pode ser alternativa interessante de reciclagem de fósforo, visto que este nutriente tem disponibilidade finita (LOPES et al., 2004).

A acidez potencial, como verificado em dezembro de 2007, aumentou de forma linear também em 2009 (Tabela 6). Rozane et al. (2013), em estudo com o subproduto da indústria processadora de goiabas, constataram incremento da acidez potencial em função da elevação das doses do subproduto. A mineralização da matéria orgânica libera para o meio íons $\mathrm{H}^{+}$, diminuindo, assim, o valor $\mathrm{pH}$ e elevando $(\mathrm{H}+\mathrm{Al})$. Boeira et al. (2002), em estudo de mineralização de nitrogênio proveniente de lodo, também observaram diminuição do valor $\mathrm{pH}$.

Houve decréscimo linear da saturação por bases, em função da aplicação do subproduto (Tabela 6). É bastante conhecida a relação inversa entre $\mathrm{V} \%$ e acidez potencial do solo. Apesar disso, $\mathrm{o}$ valor $\mathrm{pH}$ não mostrou alteração significativa até a presente amostragem. Isso pode indicar que o tempo é um fator a ser considerado para a completa reação de mineralização, o que representa vantagem da aplicação do resíduo. 
É importante destacar, também, que a pesquisa foi realizada em condições de campo, com uma fruteira perene, grande acumuladora de reservas (NATALE et al., 2001; NATALE et al., 1996b; NATALE et al., 1995; NATALE et al., 2007), e que, no manejo do pomar, é adotada a poda, que implica a adição ao solo de enorme quantidade de material vegetal, cuja biomassa tende a auxiliar na adsorção de íons $\mathrm{H}^{+}$. Logo, devido aos muitos fatores que interferem na dinâmica dos elementos no solo (clima, manchas de solo, entre outros), alguns resultados obtidos em condições controladas (CORRÊA et al., 2005; MANTOVANI et al., 2004; SOUZA et al., 2011; ROZANE et al., 2013) demandam tempo, ou seja, há necessidade de avaliações por períodos significativos, para que se manifestem em condições de campo. Houve, também, efeito linear das doses do subproduto sobre as concentrações de ferro na amostragem realizada em 2009 (Tabelas 4 e 6).

Em 2010, a amostragem de solo revelou efeito significativo das doses do subproduto sobre o valor $\mathrm{pH}$, bem como sobre as concentrações de fósforo e manganês (Tabela 4). Com relação ao valor $\mathrm{pH}$, esta análise foi a primeira que detectou diferenças significativas, desde o início da pesquisa, em 2006, constantando-se que as aplicações do subproduto promoveram redução do valor pH (Tabela 6). Assim, os resultados obtidos nas análises anteriores, que indicavam aumento da acidez potencial e/ou diminuição da saturação por bases, foram reforçados na presente análise pela constatação da diminuição do valor pH. Souza et al. (2011) fizeram observação semelhante, porém trabalhando com o subproduto da indústria processadora de goiabas, em condições controladas.Um dos processos mais importantes de acidificação do solo é consequência da reação de nitrificação do amônio. O cátion amônio transformase no ânion nitrato, e dois hidrogênios são liberados. $\mathrm{O} \mathrm{H}^{+}$tem grande afinidade com o solo, com o qual reage, ocupando posições de troca em forma não dissociada, deslocando um cátion correspondente. Dessa maneira, o solo fica pouco mais ácido, e o nitrato, bem como os cátions básicos presentes na solução do solo são, eventualmente, lixiviados (RAIJ, 2010).

A reação ácida decorrente da nitrificação do íon amônio manifesta-se tanto pela adição de adubos nitrogenados minerais, como nos processos finais de mineralização da matéria orgânica do solo ou de subprodutos vegetais adicionados (RAIJ, 2010).

Como observado nas três últimas análises de solo, o fósforo novamente foi influenciado pela aplicação do subproduto, sendo que, com o aumento das doses, houve incremento das concentrações de $\mathrm{P}$ no solo (Figura 1). Corrêa et al. (2005) e Mantovani et al. (2004) encontraram resultados semelhantes, ou seja, o subproduto é fonte de fósforo.

Com relação ao $\mathrm{Mn}$, o melhor modelo de respostas foi o linear crescente (Tabela 6). Resultados semelhantes também foram obtidos nas análises de 2007 e 2008 . A elevação da acidez do solo promove aumentos na disponibilidade de micronutrientes catiônicos, como Zn, Mn, Cu e Fe (RAIJ, 2010).

Em 2006, a análise de solo (Tabela 1) apresentava a seguinte interpretação da fertilidade do solo, de acordo com Raij et al. (1997) para P, $\mathrm{K}, \mathrm{Ca}, \mathrm{Mg}, \mathrm{B}, \mathrm{Cu}, \mathrm{Fe}, \mathrm{Mn}, \mathrm{Zn}$ e S: baixo, médio, alto, médio, médio, alto, alto, alto, médio e baixo, respectivamente. Com o passar dos anos e as sucessivas aplicações do subproduto, observou-se que, de maneira geral, houve aumento da concentração média de fósforo; no entanto, ocorreu diminuição dos valores médios de potássio e boro. Com relação ao $\mathrm{P}$, as discussões precedentes justificam as diferenças observadas; porém, a explicação para a redução das concentrações de $\mathrm{K}$ seria o fato de este nutriente ser o mais exportado pelos frutos das goiabeiras (NATALE et al., 1994; NATALE et al., 1996b), além de estar presente no subproduto em quantidadades relativamente pequenas (Tabela 3 ). Houve, também, redução gradativa do potássio no solo, observadas nas sucessivas amostragens entre 2006 e 2010 (Tabela 4), independentemente das doses de resíduo. Assim, apesar do destacado potencial de uso agronômico do subproduto, há a necessidade de monitoramento da fertilidade do solo, a fim de evitar desequilíbrios, fazendo-se a suplementação de nutrientes, se necessário, principalmente o $\mathrm{K}$, por não fazer parte de nenhum composto orgânico.

Os resultados das análises de solo, referentes à camada de 0,20-0,40 $\mathrm{m}$, para a análise de rotina, micronutrientes e enxofre, estão apresentados na Tabela 5. Observa-se que não houve efeito significativo das doses de subproduto sobre as características avaliadas nos anos de 2006, 2007, 2008 e 2009, o que é justificável devido à aplicação do material ser realizada superficialmente, sem incorporação ao solo. A exemplo do que ocorreu na camada superior do solo, os efeitos do subproduto aplicado necessitam de tempo para se fazerem presentes e, especialmente, atingirem camadas mais profundas do solo no pomar.

Em 2010, houve incremento de fósforo na camada de 0,20-0,40 m (Tabela 5). A adição de materiais orgânicos reduz a capacidade de adsorção de P pelo solo, aumentando sua disponibilidade; a matéria orgânica, por sua vez, bloqueia os sítios de adsorção dos óxidos de $\mathrm{Fe}$ e $\mathrm{Al}$ presentes no solo, 
diminuindo a capacidade de fixação de fósforo (NOVAIS et al., 2007). Essa condição pode aumentar a mobilidade do elemento no perfil, em formas orgânicas solúveis de $\mathrm{P}$, como também acontece em ecossistemas florestais (Tabela 6).
A análise de micronutrientes e enxofre na camada subsuperficial $(0,20-0,40 \mathrm{~m})$, realizada ao longo do experimento, não mostrou resultados significativos (Tabela 5).

TABELA 1- Propriedades químicas do solo da área experimental.

\begin{tabular}{|c|c|c|c|c|c|c|c|c|c|c|c|c|}
\hline Amostra & Camada & $\mathrm{pH}\left(\mathrm{CaCl}_{2}\right)$ & M.O. & $P$ res. & $\mathbf{K}$ & $\mathbf{C a}$ & Mg & $(\mathbf{H}+\mathbf{A l})$ & SB & $\mathbf{T}$ & $\mathbf{A l}$ & $\mathbf{V}$ \\
\hline & $\mathbf{m}$ & & \multicolumn{2}{|c|}{$\mathrm{g} \mathrm{dm}^{-3} \mathrm{mg} \mathrm{dm}^{-3}$} & ---- & 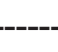 & $---\mathbf{m i}$ & $\operatorname{nol}_{\mathrm{c}} \mathrm{dm}^{-3}$ & ---- & 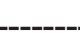 & -- & $\%$ \\
\hline Projeção copa & $0,00-0,20$ & 5,3 & 11 & 8 & 2,7 & 18 & 6 & 16 & 26,7 & 42,7 & 0,0 & 63 \\
\hline Projeção copa & $0,20-0,40$ & 5,3 & 8 & 6 & 2,0 & 25 & 19 & 18 & 46,0 & 64,0 & 0,0 & 72 \\
\hline Entrelinha & $0,00-0,20$ & 5,5 & 11 & 12 & 3,5 & 23 & 6 & 15 & 32,5 & 47,5 & 0,0 & 68 \\
\hline \multirow[t]{3}{*}{ Entrelinha } & $0,20-0,40$ & 5,4 & 8 & 5 & 2,5 & 17 & 7 & 20 & 26,5 & 46,5 & 0,0 & 57 \\
\hline & Camada & B & $\mathbf{C u}$ & $\mathbf{F e}$ & Mn & Zn & $\mathrm{SO}_{4}{ }^{2-}$ & & & & & \\
\hline & $\mathbf{m}$ & \multicolumn{6}{|c|}{ 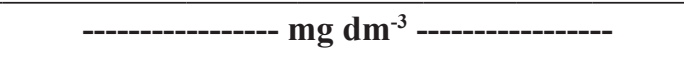 } & & & & & \\
\hline Projeção copa & $0,00-0,20$ & 0,23 & 14,7 & 19,0 & 26,6 & 0,7 & 1 & & & & & \\
\hline Projeção copa & $0,20-0,40$ & 0,16 & 5,5 & 13,0 & 18,9 & 0,4 & 1 & & & & & \\
\hline Entrelinha & $0,00-0,20$ & 0,16 & 18,2 & 15,0 & 22,4 & 0,8 & 1 & & & & & \\
\hline Entrelinha & $0,20-0,40$ & 0,16 & 5,2 & 2,0 & 17,5 & 0,4 & 1 & & & & & \\
\hline
\end{tabular}

TABELA 2- Propriedades químicas e granulométricas da área experimental, na entrelinha das goiabeiras, para fins de classificação pedológica do solo.

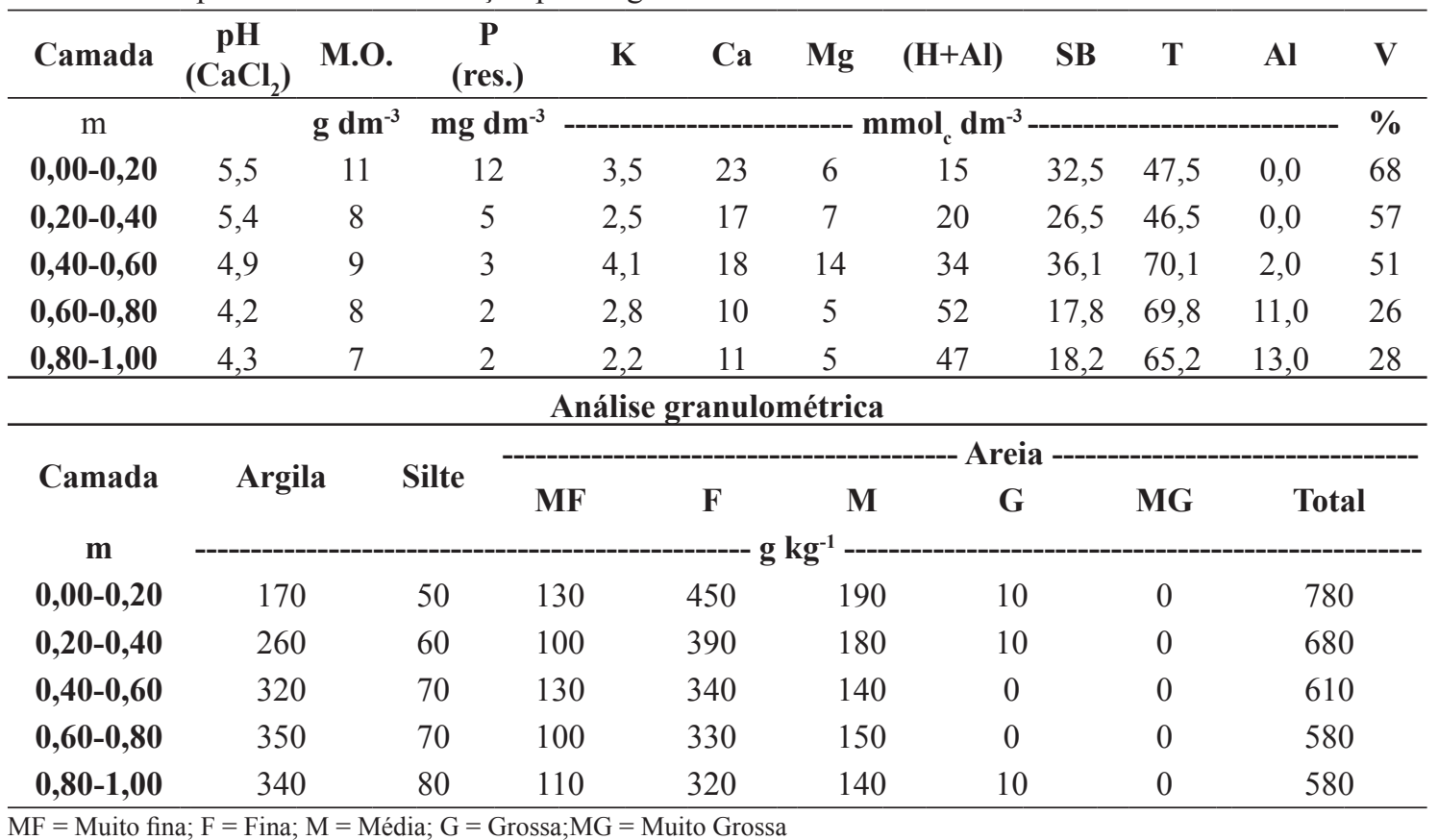

TABELA 3- Teores de macro e micronutrientes (base seca), relação C/N no subproduto.

\begin{tabular}{|c|c|c|c|c|c|c|c|c|c|c|c|c|c|}
\hline Amostra & $\mathbf{N}$ & C & $\mathbf{P}$ & $\mathbf{K}$ & $\mathrm{Ca}$ & Mg & $\mathbf{S}$ & B & $\mathrm{Cu}$ & $\mathbf{F e}$ & Mn & Zn & $\mathrm{C} / \mathrm{N}$ \\
\hline & & - & -- & & & -... & & & --- & I & -- & & \\
\hline Subproduto & 11,6 & 290 & 2,1 & 2,3 & 0,8 & 0,9 & 1,3 & 10 & 10 & 150 & 12 & 28 & 25 \\
\hline
\end{tabular}


TABELA 4 - Efeitos de doses do subproduto da agroindústria processadora de goiabas sobre atributos químicos do solo em pomar de goiabeiras, camada de 0-0,20 m, nas amostragens realizadas de 2006 a 2010 na projeção da copa.

\begin{tabular}{|c|c|c|c|c|c|c|c|c|c|c|c|c|c|c|c|c|}
\hline \multirow{3}{*}{$\begin{array}{c}\text { Resíduo } \\
\text { t ha }^{-1}\end{array}$} & \multirow{3}{*}{$\begin{array}{c}\mathrm{pH} \\
\left(\mathrm{CaCl}_{2}\right)\end{array}$} & \multicolumn{2}{|c|}{ M.O. P (res.) } & $\mathbf{K}$ & $\mathrm{Ca}$ & Mg & $\mathbf{H}+\mathbf{A l}$ & SB & $\mathbf{T}$ & $\mathbf{V}$ & B & \multirow[t]{2}{*}{$\mathbf{C u}$} & $\mathrm{Fe}$ & Mn & Zn & $\mathrm{S}_{-\mathrm{SO}_{4}}^{2}$ \\
\hline & & \multirow{2}{*}{\multicolumn{2}{|c|}{$\mathrm{g} \mathrm{dm}^{-3} \mathrm{mg} \mathrm{dm}^{-3}$}} & 3--- & 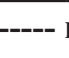 & $\mathrm{mmo}$ & $\mathrm{l}_{\mathrm{c}} \mathrm{dm}$ & $-3-$ & 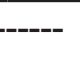 & $\%$ & 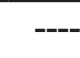 & & mo & $\mathrm{d} \mathrm{dm}^{-3}$ & ---- & -2 \\
\hline & & & & \multicolumn{6}{|c|}{2006} & & & & & & & \\
\hline $\mathbf{0}$ & 5,1 & 14 & 8 & 2,7 & 16 & 6 & 20 & 25,9 & 46,7 & 55 & 0,24 & 8,9 & 17 & 16,8 & 0,4 & 2 \\
\hline 9 & 5,2 & 14 & 12 & 2,2 & 17 & 7 & 19 & 27,9 & 46,9 & 59 & 0,23 & 10,6 & 17 & 18,0 & 0,5 & 2 \\
\hline 18 & 4,9 & 12 & 7 & 1,8 & 14 & 6 & 18 & 21,8 & 40,3 & 54 & 0,25 & 10,6 & 18 & 18,0 & 0,4 & 3 \\
\hline 27 & 4,9 & 11 & 11 & 1,9 & 12 & 5 & 20 & 19,7 & 39,7 & 49 & 0,24 & 8,1 & 17 & 17,8 & 0,4 & 2 \\
\hline 36 & 5,0 & 13 & 11 & 2,1 & 16 & 7 & 18 & 25,3 & 43,8 & 57 & 0,24 & 10,2 & 16 & 17,6 & 0,4 & 2 \\
\hline Efeito & ns & ns & ns & ns & ns & ns & ns & ns & ns & $\mathrm{ns}$ & ns & ns & ns & $\mathrm{ns}$ & ns & $\mathrm{ns}$ \\
\hline CV (\%) & 4,0 & 9,5 & 44,8 & 15,32 & 20,0 & 24,8 & 16,6 & 18,1 & 9,8 & 13,5 & 10,8 & 30,8 & 17,9 & 17,0 & 18,5 & 41,9 \\
\hline \multicolumn{17}{|c|}{2007} \\
\hline $\mathbf{0}$ & 5,3 & 13 & 15 & 1,9 & 27 & 16 & 15 & 44,9 & 59,9 & 75 & 0,13 & 9,2 & 12 & 11,4 & 0,6 & 2 \\
\hline 9 & 5,4 & 13 & 20 & 1,4 & 25 & 16 & 17 & 42,4 & 54,4 & 78 & 0,15 & 10,0 & 15 & 15,6 & 0,6 & 2 \\
\hline 18 & 5,2 & 13 & 20 & 1,6 & 21 & 14 & 19 & 40,6 & 57,6 & 70 & 0,15 & 12,3 & 15 & 16,1 & 0,6 & 2 \\
\hline 27 & 5,2 & 13 & 22 & 1,8 & 21 & 15 & 19 & 38,8 & 56,8 & 68 & 0,16 & 10,8 & 16 & 17,0 & 0,5 & 3 \\
\hline 36 & 5,3 & 15 & 33 & 1,9 & 21 & 15 & 21 & 37,9 & 58,9 & 64 & 0,20 & 14,0 & 18 & 22,0 & 0,6 & 2 \\
\hline Efeito & ns & ns & $\mathrm{L}^{*}$ & ns & $\mathrm{L}^{*}$ & ns & $\mathrm{L}^{* *}$ & ns & ns & ns & $\mathrm{L}^{* *}$ & ns & ns & $\mathrm{L}^{*}$ & ns & ns \\
\hline CV (\%) & 5,4 & 7,9 & 31 & 23,82 & 28,5 & 19,3 & 10,8 & 15,5 & 8,7 & 7,8 & 15,0 & 31,7 & 23,5 & 24,4 & 20,8 & 34,5 \\
\hline \multicolumn{17}{|c|}{2008} \\
\hline 0 & 5,3 & 12 & 9 & 1,5 & 26 & 15 & 21 & 42,7 & 62,7 & 67 & 0,17 & 11,3 & 11 & 25,9 & 0,8 & 1 \\
\hline 9 & 5,4 & 14 & 15 & 1,9 & 25 & 15 & 20 & 41,9 & 61,9 & 67 & 0,18 & 11,0 & 12 & 28,7 & 1,0 & 2 \\
\hline 18 & 5,3 & 13 & 21 & 1,5 & 23 & 15 & 22 & 39,5 & 61,5 & 64 & 0,20 & 13,5 & 14 & 32,2 & 0,8 & 1 \\
\hline 27 & 5,2 & 13 & 33 & 2,0 & 24 & 17 & 25 & 42,0 & 67,0 & 63 & 0,21 & 14,1 & 16 & 33,6 & 1,0 & 1 \\
\hline 36 & 5,0 & 15 & 35 & 1,7 & 22 & 13 & 27 & 36,7 & 63,7 & 57 & 0,23 & 17,7 & 22 & 42,7 & 1,0 & 1 \\
\hline Efeito & ns & ns & $\mathrm{L}^{* *}$ & ns & ns & ns & ns & $\mathrm{ns}$ & ns & $\mathrm{ns}$ & $\mathrm{L}^{* *}$ & $\mathrm{~L}^{*}$ & $\mathrm{~L}^{* *}$ & $\mathrm{~L}^{*}$ & $\mathrm{~ns}$ & ns \\
\hline CV $(\%)$ & 4,6 & 13,2 & 40,4 & 26,32 & 20,4 & 26,9 & 19,8 & 21,6 & 9,5 & 13,6 & 611,8 & 20,7 & 23,3 & 22,7 & 36,5 & 31,8 \\
\hline & & & & & & & & 09 & & & & & & & & \\
\hline $\mathbf{0}$ & 5,4 & 10 & 10 & 0,9 & 27 & 13 & 14 & 40,9 & 55,2 & 74 & 0,17 & 9,6 & 12 & 18 & 0,5 & 4 \\
\hline 9 & 5,4 & 15 & 12 & 0,9 & 28 & 14 & 14 & 42,9 & 56,9 & 75 & 0,19 & 10,5 & 12 & 16,5 & 0,6 & 3 \\
\hline 18 & 5,2 & 15 & 18 & 1,0 & 24 & 14 & 19 & 39,0 & 57,8 & 68 & 0,20 & 10,7 & 14 & 20,8 & 0,6 & 4 \\
\hline 27 & 5,0 & 11 & 22 & 0,7 & 20 & 13 & 20 & 33,7 & 53,2 & 63 & 0,22 & 9,8 & 21 & 19,4 & 0,5 & 4 \\
\hline 36 & 5,0 & 15 & 29 & 0,9 & 23 & 13 & 21 & 36,9 & 58,2 & 63 & 0,20 & 14,5 & 22 & 24,7 & 0,7 & 4 \\
\hline Efeito & ns & ns & $\mathrm{L}^{* *}$ & ns & ns & ns & $\mathrm{L}^{* *}$ & ns & ns & $\mathrm{L}^{* *}$ & ns & ns & $\mathrm{L}^{*}$ & ns & ns & ns \\
\hline CV $(\%)$ & 4,5 & 19,8 & 29,2 & 26,11 & 18,8 & 21,8 & 13,9 & 18,8 & 14,4 & 7,8 & 20,1 & 35,4 & 24,6 & 18,5 & 24,1 & 30,5 \\
\hline & & & & & & & & 0 & & & & & & & & \\
\hline $\mathbf{0}$ & 6,3 & 13 & 8 & 0,9 & 27 & 11 & 15 & 38,9 & 53,9 & 72 & 0,12 & 12,1 & 13 & 18 & 0,6 & 4 \\
\hline 9 & 6,0 & 17 & 14 & 1,0 & 25 & 12 & 16 & 38,0 & 54,0 & 70 & 0,19 & 13,9 & 13 & 25 & 0,7 & 4 \\
\hline 18 & 6,2 & 12 & 14 & 0,8 & 19 & 10 & 16 & 29,8 & 45,8 & 65 & 0,17 & 13,9 & 13 & 26 & 0,4 & 4 \\
\hline 27 & 5,9 & 14 & 22 & 0,9 & 18 & 10 & 17 & 28,9 & 45,9 & 63 & 0,20 & 13,2 & 17 & 28 & 0,5 & 4 \\
\hline 36 & 5,4 & 13 & 24 & 0,9 & 19 & 11 & 20 & 30,9 & 50,9 & 61 & 0,10 & 15,5 & 23 & 32 & 0,6 & 5 \\
\hline Efeito & $\mathrm{L}^{* *}$ & ns & $\mathrm{L}^{* *}$ & ns & ns & ns & ns & ns & ns & $\mathrm{ns}$ & $\mathrm{ns}$ & $\mathrm{ns}$ & ns & $\mathrm{L}^{*}$ & ns & $\mathrm{ns}$ \\
\hline CV $(\%)$ & 6,4 & 20,2 & 35,4 & 38,12 & 27,1 & 27,7 & 16,2 & 25,1 & 13,1 & 13,3 & 50,5 & 31,3 & 36,3 & 16,5 & 42,2 & 29,8 \\
\hline
\end{tabular}

**; *; ns: significativo a $1 \% ; 5 \%$ e não significativo, respectivamente. L - Linear 
TABELA 5 - Efeitos de doses do subproduto da agroindústria processadora de goiabas sobre atributos químicos do solo em pomar de goiabeiras, camada de 0,20-0,40 $\mathrm{m}$, nas amostragens realizadas de 2006 a 2010 na projeção da copa.

\begin{tabular}{|c|c|c|c|c|c|c|c|c|c|c|c|c|c|c|}
\hline Resíduo & $\begin{array}{c}\mathrm{pH} \\
\left(\mathrm{CaCl}_{2}\right)\end{array}$ & М.O. & P (res.) & $\mathbf{K}$ & $\mathrm{Ca}$ & $\mathbf{M g ~ H}+\mathbf{A l}$ & SB & $\mathbf{T}$ & $\mathbf{V}$ & B & $\mathrm{Cu}$ & $\mathbf{F e}$ & Mn & $\mathrm{Zn} \mathrm{S}-\mathrm{SO}_{4}^{2}$ \\
\hline
\end{tabular}

2006

\begin{tabular}{|c|c|c|c|c|c|c|c|c|c|c|c|c|c|c|c|c|}
\hline 0 & 5,1 & 8 & 5 & 2,0 & 13 & 5 & 18 & 20,8 & 39,0 & 52 & 0,19 & 2,4 & 12 & 15,5 & 0,2 & 6 \\
\hline 9 & 5,2 & 9 & 4 & 1,7 & 15 & 6 & 16 & 22,9 & 39,4 & 57 & 0,19 & 3,6 & 13 & 16,2 & 0,2 & \\
\hline 18 & 5,0 & 8 & 3 & 1,8 & 12 & 5 & 17 & 20,0 & 37,5 & 53 & 0,18 & 2,4 & 11 & 14,0 & 0,4 & \\
\hline 27 & 5,0 & 8 & 3 & 1,8 & 11 & 5 & 18 & 18,8 & 37,0 & 50 & 0,17 & 2,3 & 11 & 12,9 & 0,2 & . \\
\hline 36 & 5,1 & 8 & 3 & 1,6 & 11 & 5 & 16 & 18,9 & 35,1 & 53 & 0,17 & 2,5 & 11 & 14,8 & 0,2 & 7 \\
\hline Efeito & ns & ns & ns & ns & ns & ns & ns & ns & $\mathrm{ns}$ & ns & $\mathrm{ns}$ & ns & $\mathrm{ns}$ & ns & ns & \\
\hline$V(\%)$ & 3,3 & 3,5 & 43,9 & 5,3 & 28,5 & 25,9 & 13,2 & 24,2 & 15,0 & 12,0 & 12,5 & 33,0 & 13,4 & 20,0 & 44,9 & 40,4 \\
\hline \multicolumn{17}{|c|}{2007} \\
\hline 0 & 5,1 & 9 & 8 & 2,6 & 23 & 10 & 17 & 35,6 & 52,6 & 67 & 0,14 & 3,5 & 10 & 13,0 & 0,2 & 2 \\
\hline 9 & 5,2 & 10 & 12 & 2,9 & 37 & 15 & 18 & 54,9 & 72,9 & 75 & 0,14 & 2,2 & 8 & 14,2 & 0,2 & 2 \\
\hline 18 & 4,9 & 11 & 7 & 3,3 & 39 & 19 & 18 & 61,3 & 79,3 & 77 & 0,18 & 2,5 & 9 & 13,8 & 0,2 & 2 \\
\hline 27 & 4,9 & 10 & 11 & 2,4 & 21 & 10 & 18 & 33,4 & 51,4 & 65 & 0,13 & 2,2 & 9 & 14,3 & 0,2 & 3 \\
\hline 36 & 5,0 & 10 & 11 & 2,5 & 24 & 9 & 18 & 33,5 & 51,5 & 65 & 0,15 & 2,5 & 9 & 15,0 & 0,2 & 2 \\
\hline Efeito & ns & $\mathrm{ns}$ & $\mathrm{ns}$ & ns & ns & ns & ns & ns & ns & ns & ns & ns & ns & ns & ns & ns \\
\hline$(\%)$ & 4,0 & 11,0 & 32,5 & 15,3 & 34,7 & 31,3 & 9,9 & 32,0 & 35,8 & 11,5 & 18,5 & 28,3 & 12,7 & 24,4 & 19,2 & 26,6 \\
\hline \multicolumn{17}{|c|}{2008} \\
\hline $\mathbf{0}$ & 5,1 & 10 & 8 & 1,8 & 21 & 9 & 24 & 31,6 & 55,6 & 56 & 0,15 & 6,4 & 12 & 38,3 & 0,5 & 3 \\
\hline 9 & 5,1 & 10 & 10 & 1,8 & 22 & 9 & 23 & 33,1 & 56,1 & 57 & 0,14 & 5,5 & 11 & 31,7 & 0,3 & 3 \\
\hline 18 & 5,3 & 10 & 12 & 1,7 & 26 & 10 & 22 & 37,2 & 59,2 & 63 & 0,14 & 6,9 & 10 & 33,8 & 0,3 & 2 \\
\hline 27 & 5,2 & 10 & 12 & 1,8 & 23 & 10 & 24 & 33,6 & 57,6 & 58 & 0,14 & 6,3 & 11 & 32,4 & 0,3 & 3 \\
\hline 36 & 5,1 & 9 & 6 & 1,5 & 20 & 7 & 25 & 28,5 & 53,5 & 53 & 0,13 & 4,3 & 10 & 32,4 & 0,1 & 2 \\
\hline Efeito & ns & ns & ns & ns & ns & ns & ns & ns & ns & ns & ns & ns & ns & ns & ns & ns \\
\hline$V(\%)$ & 2,5 & 9,5 & 20,0 & 24,3 & 14,7 & 26,4 & 6,8 & 16,6 & 9,4 & 8,3 & 10,7 & 47,2 & 19,5 & 14,9 & 21,1 & 44,8 \\
\hline \multicolumn{17}{|c|}{2009} \\
\hline o & 5,2 & 9 & 6 & 1,1 & 21 & 9 & 19 & 31,1 & 50,1 & 62 & 0,16 & 8,9 & 11 & 23,6 & 0,3 & 2 \\
\hline 9 & 5,2 & 10 & 8 & 0,9 & 21 & 9 & 18 & 30,9 & 48,9 & 63 & 0,16 & 5,9 & 12 & 21,7 & 0,5 & 3 \\
\hline 18 & 4,8 & 10 & 7 & 0,7 & 21 & 13 & 21 & 34,7 & 55,7 & 62 & 0,15 & 4,1 & 10 & 18,2 & 0,4 & 3 \\
\hline 27 & 5,0 & 9 & 8 & 0,8 & 17 & 8 & 20 & 25,8 & 45,8 & 56 & 0,16 & 4,1 & 11 & 16,9 & 0,4 & 3 \\
\hline 36 & 5,1 & 12 & 10 & 0,9 & 19 & 9 & 19 & 28,9 & 47,9 & 60 & 0,13 & 5,3 & 12 & 25,8 & 0,4 & 3 \\
\hline Efeito & ns & ns & ns & ns & ns & ns & ns & ns & ns & ns & ns & ns & ns & ns & ns & ns \\
\hline $7 \%$ & 5,4 & 19,8 & 41,9 & 24,8 & 20,1 & 33,7 & 11,8 & 22,6 & 12,7 & 11,1 & 14,2 & 48,1 & 16,4 & 28,9 & 25,4 & 38,5 \\
\hline \multicolumn{17}{|c|}{2010} \\
\hline 0 & 5,9 & 8 & 3 & 0,9 & 16 & 7 & 17 & 23,9 & 40,9 & 58 & 0,10 & 3,1 & 9 & 23 & 0,2 & 3 \\
\hline 9 & 5,7 & 9 & 5 & 0,7 & 16 & 7 & 17 & 23,7 & 40,7 & 58 & 0,15 & 4,3 & 10 & 24 & 0,2 & 4 \\
\hline 18 & 5,6 & 9 & 4 & 0,7 & 16 & 7 & 17 & 23,7 & 40,7 & 58 & 0,13 & 3,4 & 9 & 23 & 0,2 & 4 \\
\hline 27 & 5,7 & 9 & 7 & 0,5 & 14 & 7 & 17 & 21,5 & 38,5 & 56 & 0,16 & 3,8 & 9 & 23 & 0,2 & 3 \\
\hline 36 & 5,7 & 9 & 7 & 0,8 & 15 & 8 & 19 & 23,8 & 42,8 & 56 & 0,26 & 4,3 & 11 & 32 & 0,3 & 5 \\
\hline Teito & ns & ns & $\mathrm{L}^{* *}$ & ns & ns & ns & ns & ns & ns & ns & ns & ns & ns & ns & $\mathrm{ns}$ & ns \\
\hline $\begin{array}{l}\text { CV (\%) } \\
\end{array}$ & 5,9 & 23,6 & 31,8 & 37,7 & 17,7 & 21,8 & 9,9 & 16,4 & 9,8 & 8,4 & 66,9 & 39,6 & 15,7 & 20,4 & 46,6 & 46,3 \\
\hline
\end{tabular}


TABELA 6 - Equações de regressão para efeito de doses de subproduto $(\mathrm{x})$ da agroindústria processadora de goiabas sobre atributos químicos do solo em pomar de goiabeiras (amostragem na projeção da copa).

\begin{tabular}{|c|c|c|c|}
\hline \multicolumn{4}{|c|}{2007 (Camada 0-0,20 m) } \\
\hline Variável & Equação & $\mathbf{R}^{2}$ & $\mathbf{F}$ \\
\hline $\mathbf{C a}$ & $y=-0,1861 x+26,2$ & 0,86 & $11,54 * *$ \\
\hline $\mathbf{H}+\mathbf{A l}$ & $y=0,15 x+15,25$ & 0,95 & $5,12 *$ \\
\hline B & $y=0,0018 x+0,1255$ & 0,83 & $5,57 * *$ \\
\hline Mn & $y=0,2522 x+11,88$ & 0,88 & $3,59 *$ \\
\hline \multicolumn{4}{|c|}{2008 (Camada 0-0,20 m) } \\
\hline Variável & Equação & $\mathbf{R}^{2}$ & $\mathrm{~F}$ \\
\hline B & $y=0,0017 x+0,168$ & 0,99 & $19,11 * *$ \\
\hline $\mathrm{Cu}$ & $y=0,1767 x+10,34$ & 0,87 & $13,11 * *$ \\
\hline $\mathbf{F e}$ & $y=0,2889 x+9,8$ & 0,89 & $19,90 * *$ \\
\hline Mn & $y=0,4278 x+24,92$ & 0,91 & $10,79 * *$ \\
\hline \multicolumn{4}{|c|}{2009 (Camada 0-0,20 m) } \\
\hline Variável & Equação & $\mathbf{R}^{2}$ & $\mathrm{~F}$ \\
\hline $\mathbf{H}+\mathbf{A l}$ & $y=0,267 x+13,65$ & 0,89 & $21,05^{* *}$ \\
\hline $\mathbf{V}$ & $y=-0,3694 x+75$ & 0,84 & $18,51 * *$ \\
\hline $\mathbf{F e}$ & $y=0,3222 x+10,35$ & 0,87 & $18,31 * *$ \\
\hline \multicolumn{4}{|c|}{2010 (Camada 0-0,20 m) } \\
\hline Variável & Equação & $\mathbf{R}^{2}$ & $\mathrm{~F}$ \\
\hline $\mathbf{p H}$ & $y=-0,0211 x+6,34$ & 0,73 & $14,59 * *$ \\
\hline Mn & $y=0,3444 x+19,6$ & 0,92 & $19,19 * *$ \\
\hline \multicolumn{4}{|c|}{2010 (Camada 0,20-0,40 m) } \\
\hline $\mathbf{P}$ & $y=0,1111 x+3,2$ & 0,78 & $23,40 * *$ \\
\hline
\end{tabular}

** e *: significativo a 1 e $5 \%$, respectivamente.

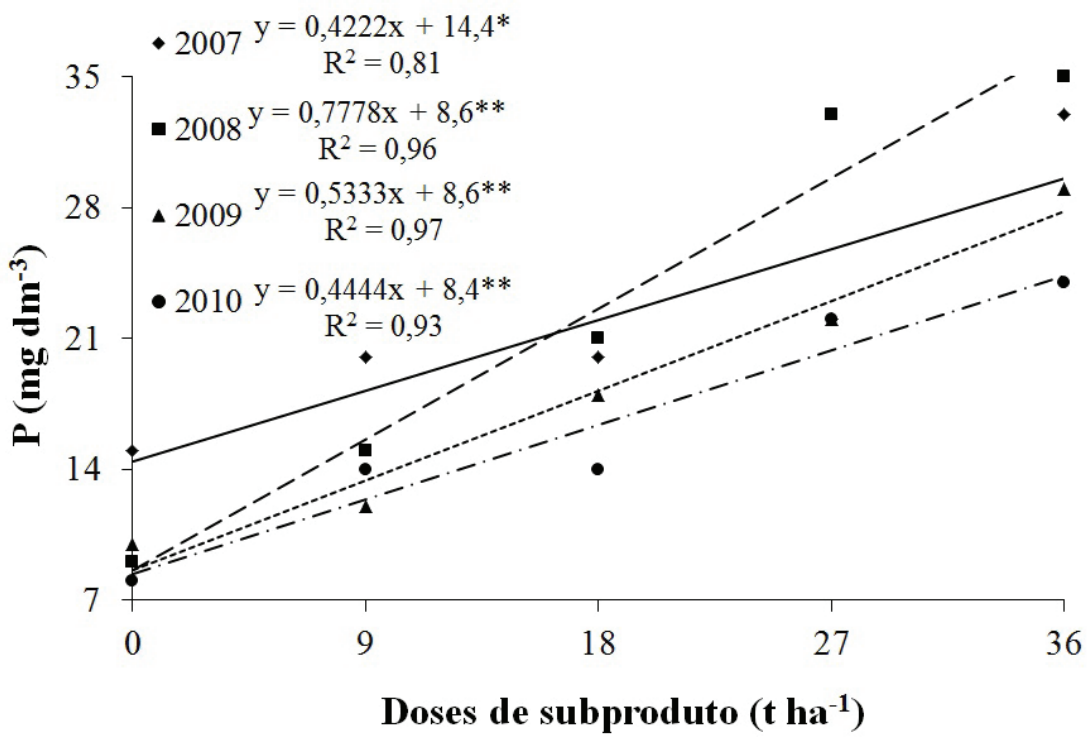

* e** - significativo a 5 e $1 \%$ de probabilidade, respectivamente.

FIGURA 1- Efeito de doses do subproduto da agroindústria processadora de goiabas sobre a concentração de fósforo na camada de 0-0,20 m em pomar de goiabeiras. 


\section{CONCLUSÕES}

A aplicação do subproduto da indústria processadora de goiabas promoveu alterações na fertilidade do solo do pomar de goiabeiras.

As doses do subproduto incrementaram, de forma efetiva, as concentrações de fósforo no solo em todas as análises realizadas. Houve aumento da concentração de manganês e redução do valor $\mathrm{pH}$ do solo nas análises finais do experimento.

Observou-se na camada subsuperfical $(0,20$ 0,40 m), após a aplicação contínua do subproduto, aumento na concentração de fósforo em função das doses de subproduto.

\section{AGRADECIMENTOS}

À FAPESP e ao CNPq, pela concessão de auxílio à pesquisa; à FAPESP, pela bolsa de doutorado ao primeiro autor; e à Indústria de Polpas e Conservas VAL Ltda., pelo auxílio na condução do ensaio.

\section{REFERÊNCIAS}

ABREU, M. F.; ANDRADE, J. C.; FALCÃO, A. A. Protocolos de análises químicas. In: ANDRADE, J. C.; ABREU, M. F. Análise química de resíduos sólidos para monitoramento e estudos agroambientais. Campinas: Instituto Agronômico, 2006. p.121-158.

ARAÚJO, F. F.; TIRITAN, C. S.; PEREIRA, H. M.; CAETANO JÚNIOR, O. Desenvolvimento do milho e fertilidade do solo após aplicação de lodo de curtume e fosforita. Revista Brasileira de Engenharia Agrícola e Ambiental, Campina Grande, v.12, p.507-511, 2008.

BOEIRA, R. C.; LIGO, M. A. V.; DYNIA, J. F. Mineralização de nitrogênio em solo tropical tratado com lodo de esgoto. Pesquisa Agropecuária Brasileira, Brasília, v.37, p.1639-1647, 2002.
BRASIL. Ministério da Agricultura, Pecuária e Abastecimento. Instrução Normativa $n^{\circ} 25$, de 23 de julho de 2009. Aprova as Normas sobre as especificações e as garantias, as tolerâncias, o registro, a embalagem e a rotulagem dos fertilizantes orgânicos simples, mistos, compostos, organominerais e biofertilizantes destinados à agricultura. Diário Oficial [da] República Federativa do Brasil, Brasília,DF, 28 jul. 2009. Seção 1, p. 20.

CHEPOTE, R. E. Efeito do composto da casca do fruto de cacau no crescimento e produção do caucaeiro. Revista Agrotrópica, Itabuna, v.15, p. 1-8, 2003.

CORRÊA, M. C. M.; FERNANDES, G. C.; PRADO, R. M.; NATALE, W. Propriedades químicas do solo tratado com resíduo orgânico da indústria processadora de goiabas. Revista Brasileira de Agrociência, Pelotas, v. 11, p. 241-243, 2005.

COSTA, M. S. S. M.; COSTA, L. A. M.; DECARLI, L. D.; PELÁ, A.; SILVA, C. J.; MATTERO, U. F.; OLIBONE, D. Compostagem de resíduos sólidos de frigorífico. Revista Brasileira de Engenharia Agrícola e Ambiental, Campina Grande, v.13, p.100-107, 2009.

EMBRAPA. Sistema brasileiro de classificação de solos. Rio de Janeiro, 1999. 412 p. (Documentos, 15).

FERREIRA, D. F. Sisvar: a computer statistical analysis system. Ciência e Agrotecnologia, Lavras, v.35, p.1039-1042, 2011.

FRANCO, C. F.; PRADO, R. M.; BRACHIROLLI, L. F.; ROZANE, D. E. Curva de crescimento e marcha de absorção de macronutrientes em mudas de goiabeira. Revista Brasileira de Ciência do Solo, Viçosa, MG, v.31, p.1429-1437, 2007.

GIANELLO, C.; DOMASZAK, S. C.; BORTOLON, L.; KRAY, C. H.; MARTINS, V. Viabilidade do uso de resíduos da agroindústria coureiro-calçadista no solo. Ciência Rural, Santa Maria, v. 41, p. 242-245, 2011.

GUIMARÃES, R. C. M.; CRUZ, M. C. P.; FERREIRA, M. E.; TANIGUCHI, C. A. K. Chemical properties of soils treated with biological sludge from gelatin industry. Revista Brasileira de Ciência do Solo, Viçosa, MG, v. 36, p. 653-660, 2012. 
IBGE- Instituto Brasileiro de Geografia e Estatística. Produção agrícola municipal. Rio de Janeiro, 2012a. v.72, 458 p.

LIMA, J. D.; MORAES, W. S.; MENDONÇA, J. C.; NOMURA, E. S. Resíduos da agroindústria de chá preto como substrato para produção de mudas de hortaliças. Ciência Rural, Santa Maria, v.37, p.1609-1613, 2007.

LOPES, A. S.; SILVA, C. A. P.; BASTOS, A. R. R. Reserva de fosfatos e produção de fertilizantes fosfatados no Brasil e no mundo. In: YAMADA, T.; ABDALLA, S. R. S. Fósforo na agricultura brasileira. Piracicaba: POTAFÓS, 2004. p.13-34.

MANTOVANI, J. R.; CORRÊA, M. C. M.; CRUZ, M. C. P.; FERREIRA, M. E.; NATALE, W. Uso fertilizante de resíduo da indústria processadora de goiabas. Revista Brasileira de Fruticultura, Jaboticabal, v.26, n.1,p.339-342, 2004.

MANTOVANI, J. R.; FERREIRA, M. E.; CRUZ, M. C. P.; BARBOSA, J. C. Alterações nos atributos de fertilidade em solo adubado com composto de lixo urbano. Revista Brasileira de Ciência do Solo, Viçosa, MG, v.29, p.817-824, 2005.

MELlO, S. C.; VITTI, G. C. Desenvolvimento do tomateiro e modificações nas propriedades químicas do solo em função da aplicação de resíduos orgânicos, sob cultivo protegido. Horticultura Brasileira, Brasília, v.20, p.200-206, 2002.

NATALE, W.; COUTINHO, E. L. M.; BOARETTO, A. E.; CENTURION, J. F. Resposta da goiabeira (Psidium guajava L.) cv. Paluma em formação à adubação fosfatada. Revista Brasileira de Fruticultura, Jaboticabal, v. 23, p. 92-96, 2001.

NATALE, W.; COUTINHO, L. E. M.; BOARETTO, A. E.; CORTEZ, G. E. P.; FETUCCIA, A. J. Extração de nutrientes por frutos de goiabeira (Psidium guajava L.). Científica, Jaboticabal, v.22, p.249253, 1994.

NATALE, W.; COUTINHO, E. L. M.; BOARETTO, A. E.; PEREIRA, F. M. Goiabeira: calagem e adubação. Jaboticabal: FUNEP, 1996a. 22 p.

NATALE, W.; COUTINHO, E. L. M.; PEREIRA, F. M.; BOARETTO, A. E.; OIOLI, A. A. P.; SALES, L. Adubação nitrogenada na cultura da goiabeira. Revista Brasileira de Fruticultura, Jaboticabal, v.17, n.1, p.7-15, 1995.
NATALE, W.; COUTINHO, E. L. M.; PEREIRA, F. M.; OIOLI, A. A. P.; SALES, L. Nutrição e adubação potássica na cultura da goiabeira. Revista Brasileira de Ciência do Solo, Viçosa, MG, v.20, p.247-250, $1996 b$.

NATALE, W.; PRADO, R. M.; ROZANE, D. E.; ROMUALDO, L. M. Efeitos da calagem na fertilidade do solo e na nutrição e produtividade da goiabeira. Revista Brasileira de Ciência do Solo, Viçosa, MG, v. 31, p.1475-1485, 2007.

NATALE, W.; ROZANE, D. E.; SOUZA, H. A.; AMORIM, D. A cultura da goiaba do plantio à comercialização. Jaboticabal: FCAV, 2009. 573p.

NOVAIS, R. F.; SMYTH, T. J.; NUNES, F. N. Fósforo. In: NOVAIS, R. F.; ALVAREZ, V. V. H.; BARROS, N. F.; FONTES, R. L. F.; CANTARUTTI, R. B.; NEVES, J. C. L. Fertilidade do solo. Viçosa: SBCS, 2007. p.471-550.

PRIMO, D. C.; FADIGAS, F. S.; CARVALHO, J. C. R.; SCHMIDT, C. D. S.; BORGES FILHO, C. D. S. Avaliação da qualidade nutricional de composto orgânico produzido com resíduos de fumo. Revista Brasileira de Engenharia Agrícola e Ambiental, Campina Grande, v.14, p.742-746, 2010.

RAIJ, B. van. Acidez e calagem. In: VALE, D. W.; SOUSA, J. I.; PRADO, R. M. Manejo da fertilidade do solo e nutrição de plantas. Jaboticabal: FCAV, 2010. p. 37-68.

RAIJ, B. van. Fertilidade do solo e manejo de nutrients. Piracicaba: IPNI, 2011. 420 p.

RAIJ, B. van; ANDRADE, J. C.; CANTARELLA, H.; QUAGGIO, J. A. Análise química para avaliação da fertilidade de solos tropicais. Campinas: Instituto Agronômico, 2001. 285 p.

RAIJ, B. van; CANTARELLA, H.; QUAGGIO, J. A.; FURLANI, A. M. C. Recomendações de adubação e calagem para o Estado de São Paulo. Campinas: Instituto Agronômico, 1997. p. 285 (Boletim Técnico, 100).

ROZANE, D. E.; TORRES, M. H.; SOUZA, H. A.; NATALE, W.; SILVA, S. H. M. G. Application of a byproduct of guava processing in an Ultisol, in the presence and absence of mineral fertilization. Idesia, Arica, v.31, p.89-96, 2013. 
SOUZA, H. A.; NATALE, W.; MODESTO, V. C.; ROZANE, D. E. Mineralização do nitrogênio proveniente da aplicação do resíduo da indústria processadora de goiabas em Argissolo. Bragantia, Campinas, v.70, p.882-887, 2011. 